\title{
UJI VIABILITAS DAN VIGOR UMBI BAWANG MERAH (Allium cepa L.) DENGAN KADAR AIR DAN SUHU PENYIMPANAN YANG BERBEDA
}

\author{
Nofripa Herlina, Novia Gesriantuti, Desi Susanti \\ Program Studi Biologi, Universitas Muhammadiyah Riau \\ email: nofripaherlina@umri.ac.id
}

\begin{abstract}
ABSTRAK
Kebutuhan masyarakat terhadap bawang merah mengalami peningkatan seiring dengan peningkatan jumlah penduduk Agar kebutuhan dapat terpenuhi, harus diimbangi dengan jumlah produksi. Tujuan dari penelitian ini adalah untuk mengetahui kadar air dan suhu penyimpanan yang optimal serta interaksi keduanya terhadap viabilitas dan vigor umbi bibit bawang merah (Allium cepa L.). Penelitian ini dilaksanakan pada bulan November 2015 sampai Februari 2016. Penelitian dilakukan secara eksperimen yang disusun berdasarkan Rancangan Acak Lengkap (RAL) yang terdiri dari dua faktor. Faktor I yaitu kadar air yang hilang terdiri dari tiga taraf: $80 \%, 85 \%$, dan $90 \%$. Faktor II yaitu suhu penyimpanan terdiri dari tiga taraf: suhu ruang $\left(27{ }^{\circ} \mathrm{C}-30{ }^{0} \mathrm{C}\right)$, suhu dingin $\left(5{ }^{\circ} \mathrm{C}\right.$ $\left.10{ }^{0} \mathrm{C}\right)$ dan suhu beku $\left(-5^{0} \mathrm{C}\right.$ sampai $\left.0{ }^{0} \mathrm{C}\right)$, masing-masing dengan empat kali ulangan. Parameter yang diamati adalah persentase kerusakan, pertumbuhan tunas, vigor dan viabilitas umbi bibit bawang merah. Hasil penelitian menunjukkan bahwa kadar air yang hilang $85 \%$ memberikan hasil yang optimal terhadap parameter vigor dan viabilitas umbi bibit bawang merah, suhu dingin (5 $\left.{ }^{0} \mathrm{C}-10{ }^{0} \mathrm{C}\right)$ dan suhu beku $\left(-5{ }^{0} \mathrm{C}\right.$ sampai $\left.0{ }^{0} \mathrm{C}\right)$ memberikan hasil yang optimal terhadap parameter vigor dan viabilitas umbi bawang merah. Interaksi antara kadar air dan suhu penyimpanan tidak berbeda nyata terhadap vigor dan viabilitas umbi bibit bawang merah.
\end{abstract}

Kata kunci : Allium cepa L., kadar air, suhu penyimpanan, vigor, viabilitas.

\section{PENDAHULUAN}

\section{Latar Belakang}

Bawang merah merupakan salah satu tanaman hortikultura yang penting untuk dikembangkan. Selain digunakan sebagai campuran bumbu masakan, bawang merah juga dimanfaatkan untuk obat-obatan.

Menurut Maemunah (2010),
kebutuhan masyarakat terhadap bawang merah dari tahun ke tahun mengalami peningkatan seiring dengan peningkatan jumlah penduduk dan daya beli masyarakat yang cenderung naik. Agar kebutuhan dapat terpenuhi, harus diimbangi dengan jumlah produksi. Untuk meningkatkan produksi bawang merah dapat dilakukan dengan penggunaan bibit bermutu tinggi. Ketersediaan bibit bermutu 
tinggi masih sangat terbatas, sehingga petani menanam bibit apa adanya (bermutu rendah) dan akibatnya produksi yang dihasilkan sangat rendah dan berumbi kecil (Maemunah, 2010).

Bibit bawang merah vegetatif (umbi semu) memiliki kadar air tinggi, sehingga membutuhkan proses penyimpanan yang sesuai agar dapat mempertahankan viabilitas selama penyimpanan (Sopha, 2010). Untuk mempertahankan viabilitas selama penyimpanan, maka bibit harus dikeringkan terlebih dahulu sesuai dengan sifat bibit tersebut, bibit bawang merah yang berupa umbi semu relatif memiliki sifat yang sama dengan benih rekalsitran. Rekalsitran merupakan bibit yang tidak dapat bertahan hidup pada kadar air yang relatif tinggi (20\%$50 \%$ ) sehingga tidak dapat disimpan untuk waktu yang lama (Maemunah, 2010).

Penyimpanan bibit bawang merah yang masih kurang tepat dikhawatirkan akan meningkatkan jumlah kerusakan bibit bawang merah dan pertumbuhan tunas sebelum waktunya. Hal ini menyebabkan kurangnya ketersediaan bibit bawang merah yang berkualitas. Penyimpanan bibit bawang merah yang tepat tentunya dapat mengurangi kerusakan dan pertumbuhan tunas pada bibit bawang merah.

Nurkomar, et al. (2001), melakukan penelitian tentang penyimpanan bawang merah pada suhu $10^{\circ} \mathrm{C}, 20^{\circ} \mathrm{C}$ dengan kelembaban relative (RH) $75 \% \quad-80 \%$ hasil terbaik yaitu pada suhu penyimpanan $10^{\circ} \mathrm{C}$ dengan kelembaban relatif (RH) 75\%-80\% menghasilkan kadar air akhir sebesar $83.41 \%$ dari kadar air awal sebesar 87\%, setara dengan kehilangan berat sebesar $3.59 \%$. Mutia et al. (2014), juga melaporkan bahwa penyimpanan bawang merah dengan kadar air $80 \%$ dan penyimpanan pada suhu $5^{\circ} \mathrm{C}$ memberikan kualitas terbaik yang menghasilkan susut bobot 7,06\%, kadar air 79,48\%, kerusakan 0,37\%, kekerasan 4,18 N, dan VRS (Volatil Reducing Substance) $26,53 \mu \mathrm{Eq} / \mathrm{g}$ selama penyimpanan 8 minggu.

Berdasarkan latar belakang tersebut maka perlu dilakukan penelitian tentang viabilitas dan vigor umbi bibit bawang merah (Allium cepa L.) dengan kadar air dan suhu penyimpanan yang berbeda.

\section{METODOLOGI}

Penelitian dilakukan di Laboratorium Biologi Fakultas MIPA dan Kesehatan Universitas Muhammadiyah Riau, dari bulan November 2015 sampai Februari 2016. Alat yang digunakan pada penelitian ini adalah timbangan analitik, cawan petri, lemari pendingin (kulkas dan freezer), termometer, alumunium foil, kamera digital, kertas label dan polibag (ukuran polibag $10 / 5 \times 15 \mathrm{~cm} \times 0,05$ ). Bahan yang digunakan pada penelitian ini adalah umbi bawang 
merah varietas Bima Brebes, tanah humus, pupuk kandang dan air.

Penelitian dilakukan secara eksperimen dalam bentuk faktorial yang disusun menggunakan rancangan acak lengkap (RAL) terdiri dari dua faktor, yaitu:

Faktor I adalah suhu penyimpanan terdiri dari 3 taraf merujuk dari Sutopo, (2012) yaitu:

1. S1 : Suhu ruang (27$30^{\circ} \mathrm{C}$ )

2. $\mathrm{S} 2$ : Suhu dingin (5$\left.10^{0} \mathrm{C}\right)$

3. S3 : Suhu beku $\left(-5-0^{0} \mathrm{C}\right)$

Faktor II adalah kadar air yang terdiri dari 3 taraf, yaitu:

1. K1 : Kadar air yang hilang $80 \%$

2. K2 : Kadar air yang hilang $85 \%$

3. K3 : Kadar air yang hilang $90 \%$

Dua faktor di atas menghasilkan 9 kombinasi dengan 4 ulangan menjadi 36 satuan percobaan. Parameter yang diamati yaitu vigor dan viabilitas umbi bibit bawang merah. Data yang diperoleh dianalisis secara statistik menggunakan analisis varian (ANOVA). Jika hasil analisis varian berpengaruh nyata maka dilanjutkan dengan DMRT (Duncan Multiple Range Test) dengan taraf 5\%.

\section{HASIL DAN PEMBAHASAN}

Pengamatan terhadap umbi bibit bawang merah ( Allium cepa L.) meliputi pengamatan kerusakan, pertumbuhan tunas, vigor dan viabilitas umbi bibit bawang merah selama penyimpanan 8 minggu. Vigor dilihat pada hari ke 5 sedangkan viabilitas dilihat pada hari ke 7 setelah tanam. Data hasil penelitian persentase kerusakan, pertumbuhan tunas, vigor dan viabilitas umbi bibit bawang dapat dilihat pada Tabel 1.

Tabel 1. Persentase vigor dan viabilitas umbi bibit bawang merah ( Allium cepa L.) selama penyimpanan 8 minggu.

\begin{tabular}{|c|c|c|c|c|c|}
\hline \multirow{2}{*}{ Perlakuan } & \multirow{2}{*}{$\begin{array}{c}\text { Jumlah bibit } \\
\text { awal }\end{array}$} & $\begin{array}{c}\text { Kerusakan } \\
(\%)\end{array}$ & $\begin{array}{c}\text { Pertumbuhan } \\
\text { tunas }(\%)\end{array}$ & Vigor $(\%)$ & $\begin{array}{c}\text { Viabilitas } \\
(\%)\end{array}$ \\
\hline K1S1 & 4 & $2(50 \%)$ & $1(25 \%)$ & $1(25 \%)$ & $1(25 \%)$ \\
\hline K1S2 & 4 & $0(0 \%)$ & $1(25 \%)$ & $1(25 \%)$ & $3(75 \%)$ \\
\hline K1S3 & 4 & $2(50 \%)$ & $0(0 \%)$ & $2(50 \%)$ & $2(50 \%)$ \\
\hline K2S1 & 4 & $2(50 \%)$ & $0(0 \%)$ & $2(50 \%)$ & $2(50 \%)$ \\
\hline K2S2 & 4 & $0(0 \%)$ & $1(25 \%)$ & $3(75 \%)$ & $3(75 \%)$ \\
\hline K2S3 & 4 & $1(25 \%)$ & $0(0 \%)$ & $3(75 \%)$ & $3(75 \%)$ \\
\hline K3S1 & 4 & $3(75 \%)$ & $0(0 \%)$ & $1(25 \%)$ & $1(25 \%)$ \\
\hline K3S2 & 4 & $0(0 \%)$ & $2(50 \%)$ & $2(50 \%)$ & $2(50 \%)$ \\
\hline K3S3 & 4 & $2(50 \%)$ & $0(0 \%)$ & $2(50 \%)$ & $2(50 \%)$ \\
\hline
\end{tabular}


Ket: K1= Kadar air yang hilang $80 \%, \mathrm{~K} 2=$ Kadar air yang hilang 85\%, K3= kadar air yang hilang $90 \%$

$\mathrm{S} 1=$ Suhu Ruang $\left(27^{0}-30^{\circ} \mathrm{C}\right), \mathrm{S} 2=$ Suhu Dingin $\left(5^{0}-10^{\circ} \mathrm{C}\right), \mathrm{S} 3=$ Suhu beku $\left(-5^{0}-0^{0} \mathrm{C}\right)$

Berdasarkan hasil pengamatan

Tabel 1 menunjukkan bahwa persentase kerusakan tertinggi terdapat pada perlakuan K3S1 sebesar $75 \%$, pertumbuhan tunas tertinggi terdapat pada perlakuan K3S2 sebesar 50\%, vigor tertinggi terdapat pada perlakuan K2S2 dan
K2S3 sebesar 75\%, dan viabilitas tertinggi terdapat pada perlakuan K1S2, K2S2 dan K2S3 sebesar 75\%.

Grafik persentase kerusakan umbi bibit bawang merah dapat dilihat pada Gambar 1.

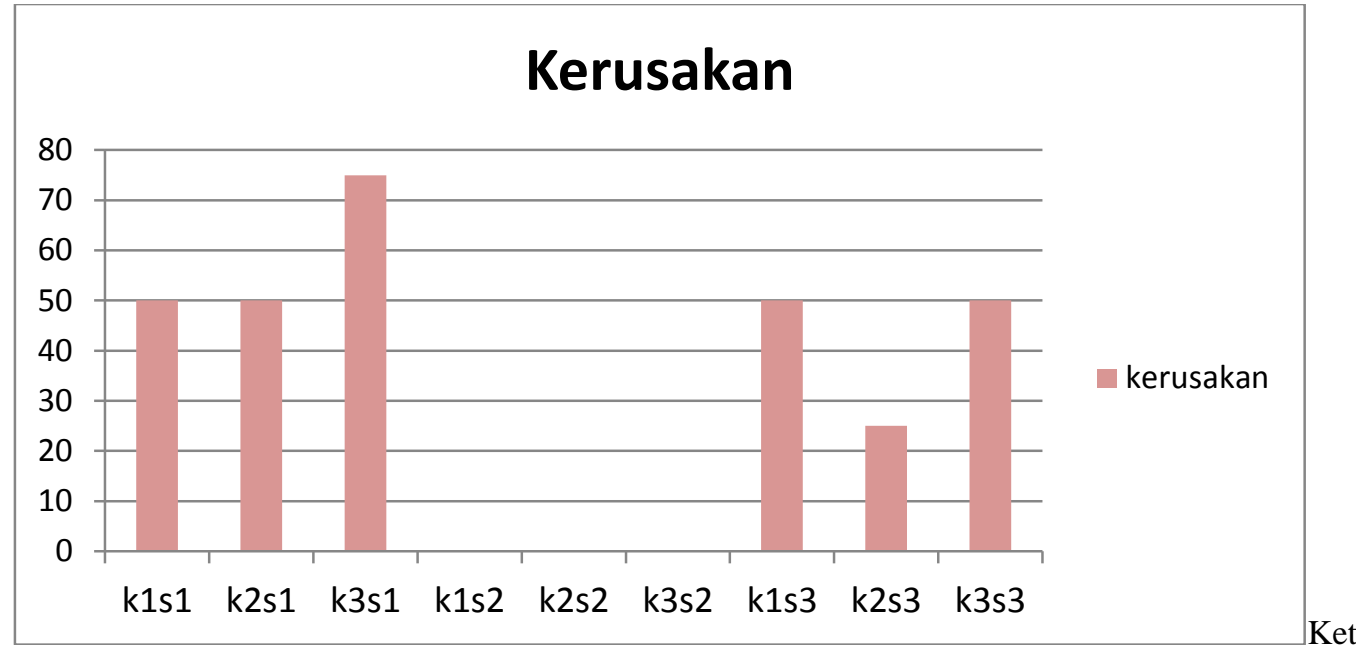

$\mathrm{K} 1=$ Kadar air yang hilang 80\%, K2= Kadar air yang hilang $85 \%, \mathrm{~K} 3=$ kadar air yang hilang $90 \%$ $\mathrm{S} 1=$ Suhu Ruang $\left(27^{0}-30^{\circ} \mathrm{C}\right), \mathrm{S} 2=$ Suhu Dingin $\left(5^{0}-10^{\circ} \mathrm{C}\right), \mathrm{S} 3=\mathrm{Suhu}$ beku $\left(-5^{0}-0^{\circ} \mathrm{C}\right)$

Gambar 1 Grafik persentase kerusakan umbi bibit bawang merah selama penyimpanan 8 minggu

Gambar 1 menunjukan bahwa persentase kerusakan tertinggi terdapat pada perlakuan K3S1, yaitu sebesar $75 \%$. Hal ini diduga kisaran suhu $27^{0}-30^{\circ} \mathrm{C}$ yang tidak tetap selama penyimpanan sehingga memicu pertumbuhan mikroorganisme pada umbi bibit bawang merah selain itu, diduga terjadi penguapan yang berlebihan sehingga menyebabkan umbi bibit bawang merah busuk (umbi bibit bawang merah menghitam dan kering). Mutia et al. (2014), menyatakan bahwa penyimpanan umbi bibit bawang merah pada suhu $25^{0}-30^{\circ} \mathrm{C}$ hingga akhir penyimpanan menghasilkan umbi bibit bawang merah busuk yang sangat tinggi. Hal ini disebabkan penggunaan suhu yang tinggi memicu pertumbuhan mikroorganisme pada umbi bibit bawang merah.

Pada suhu beku $-5{ }^{0} \mathrm{C}$ sampai 0 ${ }^{0} \mathrm{C}$ juga terjadi kerusakan (umbi bibit bawang merah lunak) pada perlakuan 
K1S3, K2S3 dan K3S3 masingmasing 50\%, 25\% dan 50\% (Tabel 1). Hal ini diduga kerusakan disebabkan oleh proses freezing injuries pada umbi bibit bawang merah. Freezing injuries atau kerusakan akibat pengkristalan air dalam umbi terjadi karena kandungan air dalam umbi masih relatif tinggi dan disimpan pada suhu $-5^{0} \mathrm{C}$. Kandungan air tersebut membentuk kristal-kristal es yang terikat di antara sel dalam umbi, kristal es tersebut kemudian mencair dan menyebabkan membran sel mengkerut sehingga proses metabolisme dalam sel terganggu. Menurut Kuswanto (2007), selama proses pembekuan kristal es tumbuh pada ruang antar sel menyebabkan perubahan bentuk (deformasi) dan kerusakan dinding sel. Kristal es mempunyai tekanan uap air yang lebih rendah dibandingkan di dalam sel sehingga air berpindah dari sel menuju kristal yang sedang tumbuh akibatnya sel mengalami dehidrasi dan secara permanen mengalami Kerusakan.

Kerusakan terendah terjadi pada perlakuan K1S2, K2S2, dan K3S2 yaitu masing-masing sebesar 0\% (Tabel 1). Hal ini diduga karena penggunaan suhu rendah mampu menghambat respirasi dan pertumbuhan mikroorganisme pada umbi bibit bawang merah selama penyimpanan 8 minggu. Maratul (2015), menyatakan bahwa pada suhu $5^{0}-10^{\circ} \mathrm{C}$ enzim-enzim yang terkandung dalam benih berada pada fase istirahat sehingga metabolisme pada benih tidak aktif.

Hasil uji statistik (Tabel 2) menunjukan bahwa suhu penyimpanan berpengaruh signifikan terhadap kerusakan umbi bibit bawang merah, sedangkan kadar air dan interaksi antara kadar air dan suhu penyimpanan berpengaruh tidak signifikan terhadap kerusakan umbi bibit bawang merah selama penyimpanan 8 minggu.

Tabel 2 Pengaruh interaksi kadar air dan suhu penyimpanan terhadap kerusakan umbi bibit bawang merah selama penyimpanan 8 minggu

\begin{tabular}{|c|c|c|c|c|}
\hline \multirow[b]{2}{*}{$\begin{array}{c}\text { Kadar air yang } \\
\text { hilang }(\%)\end{array}$} & \multicolumn{3}{|c|}{ Suhu } & \multirow{2}{*}{$\begin{array}{c}\text { Rata-rata } \\
\text { kerusakan } \\
\text { terhadap kadar } \\
\text { air }\end{array}$} \\
\hline & $\begin{array}{c}\text { Ruang } \\
\left(27^{0} \mathrm{C}-30\right. \\
\left.{ }^{0} \mathrm{C}\right)\end{array}$ & $\begin{array}{c}\text { Dingin } \\
\left(5^{0} \mathrm{C}-10{ }^{0} \mathrm{C}\right)\end{array}$ & $\begin{array}{c}\text { Beku } \\
\left(0{ }^{0} \mathrm{C}-(-\right. \\
\left.5^{0} \mathrm{C}\right)\end{array}$ & \\
\hline $80 \%$ & $0,50^{\mathrm{a}}$ & $0,00^{\mathrm{a}}$ & $0,50^{\mathrm{a}}$ & $0,33^{\mathrm{a}}$ \\
\hline $85 \%$ & $0,50^{\mathrm{a}}$ & $0,00^{\mathrm{a}}$ & $0,25^{\mathrm{a}}$ & $0,25^{\mathrm{a}}$ \\
\hline $90 \%$ & $0,75^{\mathrm{a}}$ & $0,00^{\mathrm{a}}$ & $0,50^{\mathrm{a}}$ & $0,41^{\mathrm{a}}$ \\
\hline $\begin{array}{l}\text { Rata-rata } \\
\text { kerusakan } \\
\text { terhadap suhu }\end{array}$ & $0,58^{\mathrm{b}}$ & $0,00^{\mathrm{a}}$ & $0,41^{\mathrm{b}}$ & \\
\hline
\end{tabular}

Angka-angka pada kolom dan baris yang sama yang diikuti oleh huruf yang sama tidak berbeda nyata pada uji DMRT taraf 5\%.

\subsection{Pertumbuhan Tunas}


Grafik pertumbuhan tunas umbi bibit bawang merah dapat dilihat pada

\section{Gambar 2.}

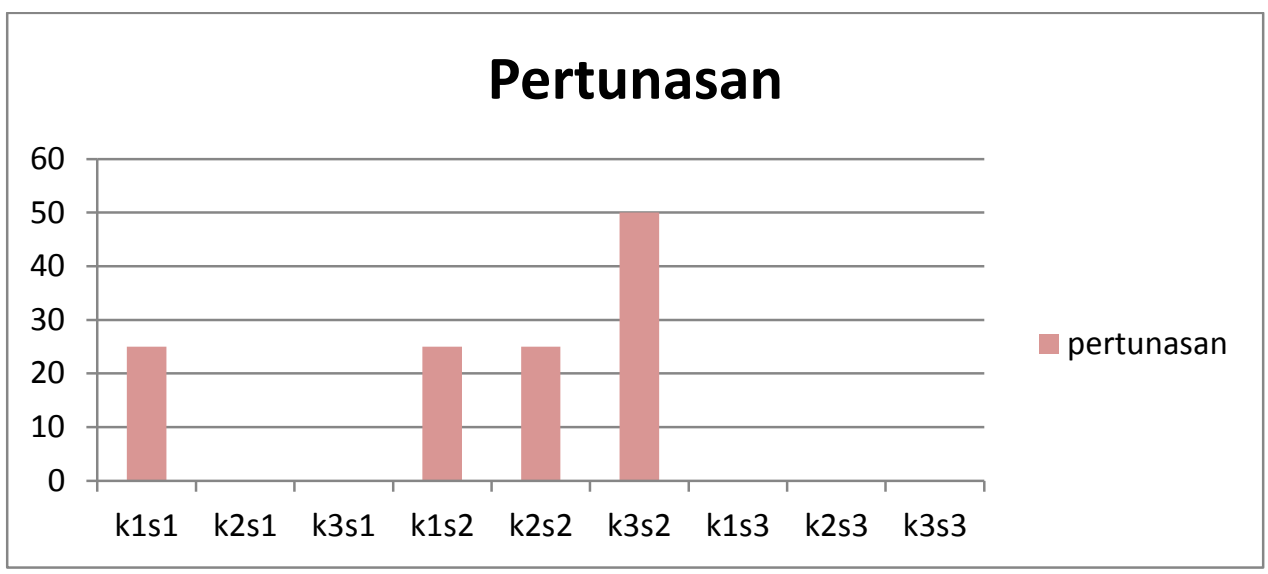

Ket: $\mathrm{K} 1=$ Kadar air yang hilang $80 \%, \mathrm{~K} 2=$ Kadar air yang hilang $85 \%, \mathrm{~K} 3=$ kadar air yang hilang $90 \%$

$\mathrm{S} 1=$ Suhu Ruang $\left(27^{0}-30^{\circ} \mathrm{C}\right), \mathrm{S} 2=\mathrm{Suhu}$ Dingin $\left(5^{0}-10^{\circ} \mathrm{C}\right), \mathrm{S} 3=\mathrm{Suhu}$ beku $\left(-5^{0}-0^{0} \mathrm{C}\right)$

Gambar 2 Grafik persentase pertumbuhan tunas umbi bibit bawang merah selama penyimpanan 8 minggu

Gambar 2 menunjukan bahwa persentase pertumbuhan tunas tertinggi terdapat pada perlakuan K3S2, yaitu sebesar 50\%. Hal ini diduga aktivitas enzim dan metabolisme didalam umbi bibit bawang merah masih aktif sehingga memicu pembentukan tunas. Mutia et al. (2014) menyatakan bahwa tingginya pertumbuhan tunas pada suhu $10^{\circ} \mathrm{C}$ disebabkan karena pada suhu tersebut terjadi peningkatan aktivitas enzim dan giberelin dalam sel, kondisi tersebut menyebabkan meningkatnya proses pembelahan sel serta patahnya dormansi yang menyebabkan terjadi perubahan penampilan dan memicu pembentukan tunas.

Berdasarkan Gambar 2 juga dapat dilihat bahwa pertumbuhan tunas terendah terdapat pada perlakuan K1S3, K2S1, K2S3, K3S1 dan K3S3 sebesar 0\%. Hal ini diduga penyimpanan pada kisaran suhu ruang $\left(27{ }^{0} \mathrm{C}-30{ }^{0} \mathrm{C}\right)$, menyebabkan umbi bibit bawang merah mengalami penguapan yang berlebihan sehingga terjadi penyusutan kadar air umbi bibit bawang merah yang menyebabkan umbi bibit tidak mampu bertunas. Pada suhu beku $\left(-5{ }^{0} \mathrm{C}-0{ }^{0} \mathrm{C}\right)$ umbi bibit bawang merah mengalami kerusakan yang disebabakan oleh freezing injury pada umbi bibit bawang merah, kadar air yang terdapat diantara jaringan sel membeku membentuk kristal es, metabolisme terhenti dan sel-sel akan mati dan kemudian membusuk sehingga tidak terjadi pertumbuhan 
tunas. Andreas (2013), menyatakan bahwa suhu sendiri memberikan pengaruh terhadap pertumbuhan tunas, penyimpanan pada suhu $5^{0} \mathrm{C}$ memiliki persentase pertumbuhan tunas lebih besar di bandingkan dengan suhu $-5^{\circ} \mathrm{C}$ dan suhu ruang.

Hasil uji statistik (Tabel 3) menunjukan bahwa suhu penyimpanan berpengaruh nyata terhadap pertumbuhan tunas umbi bibit bawang merah, sedangkan kadar air dan interaksi antara kadar air dan suhu penyimpanan berpengaruh tidak nyata terhadap pertumbuhan tunas umbi bibit bawang merah.

Tabel 3 Pengaruh interaksi kadar air dan suhu penyimpanan terhadap pertumbuhan tunas umbi bibit bawang merah selama penyimpanan 8 minggu.

\begin{tabular}{|c|c|c|c|c|}
\hline \multirow{2}{*}{$\begin{array}{c}\text { Kadar air yang } \\
\text { hilang }(\%)\end{array}$} & \multicolumn{3}{|c|}{ Suhu } & \multirow{2}{*}{$\begin{array}{c}\text { Rata-rata } \\
\text { pertumbuhan } \\
\text { tunas terhadap } \\
\text { kadar air }\end{array}$} \\
\cline { 2 - 4 } & $\begin{array}{c}\text { Ruang } \\
\left(27^{\circ} \mathrm{C}-30\right. \\
\left.{ }^{0} \mathrm{C}\right)\end{array}$ & $\begin{array}{c}\text { Dingin } \\
\left(5^{\circ} \mathrm{C}-10^{\circ} \mathrm{C}\right)\end{array}$ & $\begin{array}{c}\text { Beku } \\
\left(0{ }^{\circ} \mathrm{C}-\left(-5^{\circ} \mathrm{C}\right)\right.\end{array}$ & $0,16^{\mathrm{a}}$ \\
\hline $80 \%$ & $0,25^{\mathrm{a}}$ & $0,25^{\mathrm{a}}$ & $0,00^{\mathrm{a}}$ & $0,08^{\mathrm{a}}$ \\
\hline $85 \%$ & $0,00^{\mathrm{a}}$ & $0,25^{\mathrm{a}}$ & $0,00^{\mathrm{a}}$ & $0,16^{\mathrm{a}}$ \\
\hline $90 \%$ & $0,00^{\mathrm{a}}$ & $0,50^{\mathrm{a}}$ & $0,00^{\mathrm{a}}$ & \\
\hline $\begin{array}{c}\text { Rata-rata } \\
\begin{array}{c}\text { pertumbuhan } \\
\text { tunas terhadap } \\
\text { suhu }\end{array}\end{array}$ & $0,08^{\mathrm{ab}}$ & $0,33^{\mathrm{b}}$ & $0,00^{\mathrm{a}}$ & \\
\hline
\end{tabular}

Angka-angka pada kolom dan baris yang sama yang diikuti oleh huruf yang sama tidak berbeda nyata pada uji DMRT taraf 5\%.

\subsection{Vigor}

Grafik persentase vigor umbi bibit bawang merah selama penyimpanan 8

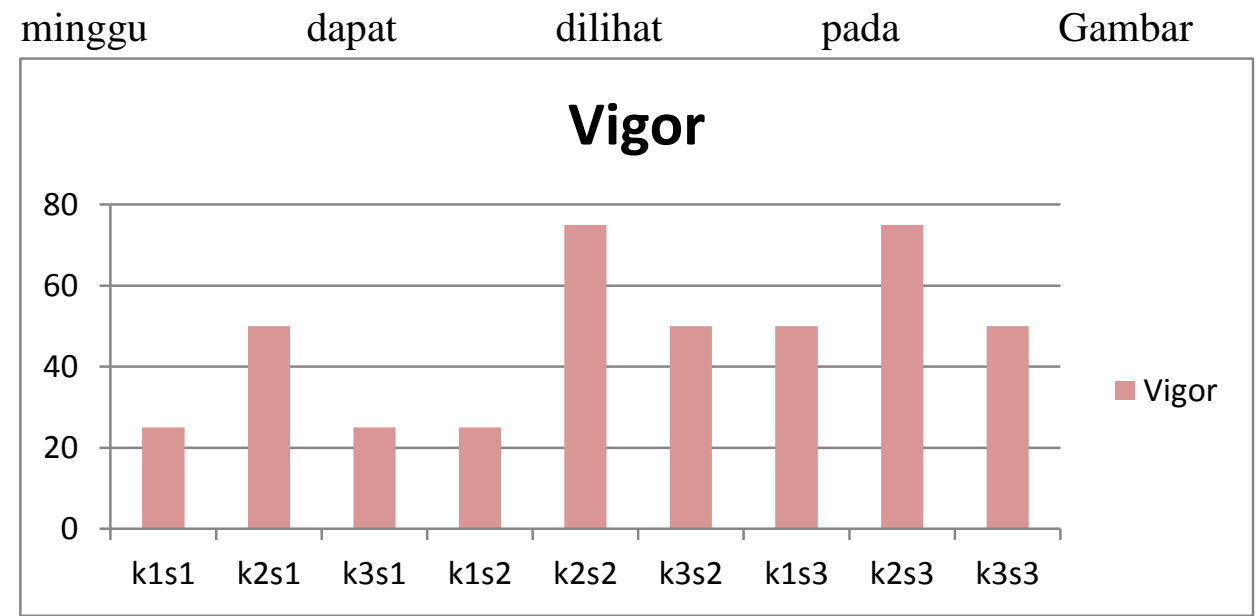

Ket: K1= Kadar air yang hilang 80\%, K2= Kadar air yang hilang 85\%, K3= kadar air yang hilang $90 \%$ 
$\mathrm{S} 1=$ Suhu Ruang $\left(27^{0}-30{ }^{\circ} \mathrm{C}\right), \mathrm{S} 2=$ Suhu Dingin $\left(5^{0}-10^{\circ} \mathrm{C}\right), \mathrm{S} 3=$ Suhu beku $\left(-5^{0}-0^{\circ} \mathrm{C}\right)$

Gambar 3 Grafik persentase vigor umbi bibit bawang merah selama penyimpanan 8 minggu

Gambar 3 menunjukkan bahwa persentase vigor tertinggi terdapat pada perlakuan $\mathrm{K} 2 \mathrm{~S} 2$ dan $\mathrm{K} 2 \mathrm{~S} 3$ sebesar 75\%, hal ini diduga karena kadar air $85 \%$ (K2) yang digunakan mampu mempertahankan vigornya, sehingga jika diberi perlakuan penyimpanan pada suhu dingin $\left(5^{0} \mathrm{C}\right.$ $\left.-10{ }^{0} \mathrm{C}\right)$ dan suhu beku $\left(-5{ }^{0} \mathrm{C}-0{ }^{0} \mathrm{C}\right)$ umbi bibit bawang merah masih memiliki vigor yang baik setelah penyimpanan selama 8 minggu. Kuswanto (2007), menyatakan bahwa penyimpanan suhu rendah mampu menahan kenaikan persentase kerusakan umbi bibit bawang merah. Selain itu Sari (2010), yang menyatakan bahwa pada benih yang memiliki kadar air benih yang sesuai untuk penyimpanan maka daya kecambah benih dapat dipertahankan selama penyimpanan.

Gambar 3 juga menunjukan bahwa Vigor terendah terdapat pada perlakuan K1S1, K1S2, dan K3S1 dengan nilai vigor berturut-turut sebesar 25\%. Hal ini diduga karena penyimpanan pada suhu ruang $\left(27^{\circ} \mathrm{C}-30^{\circ} \mathrm{C}\right)$ umbi bibit bawang merah mengalami metabolisme yang menyebabkan cadangan makanan tidak cukup untuk berkecambah, sedangkan pada suhu dingin $\left(5^{0}-10\right.$ $\left.{ }^{0} \mathrm{C}\right)$ umbi bibit bawang merah mengalami dormansi, sehingga butuh waktu untuk beradaptasi dengan lingkungan pada saat ditanam. Hario (2009) menyatakan bahwa periode simpan yang relatif singkat (1 s/d 3 bulan) belum memberikan pengaruh yang signifikan terhadap penurunan daya tumbuh benih.

Hasil uji statistik (Tabel 4) menunjukkan bahwa suhu penyimpanan berpengaruh tidak signifikan terhadap vigor umbi bibit bawang merah, sedangkan kadar air dan interaksi antara kadar air dan suhu penyimpanan juga berpengaruh tidak signifikan terhadap vigor umbi bibit bawang merah selama penyimpanan 8 minggu.

Tabel 4 Pengaruh interaksi kadar air dan suhu penyimpanan terhadap vigor umbi bibit bawang merah selama penyimpanan 8 minggu.

\begin{tabular}{|c|c|c|c|c|}
\hline \multirow[b]{2}{*}{$\begin{array}{c}\text { Kadar air yang } \\
\text { hilang }(\%)\end{array}$} & \multicolumn{3}{|c|}{ Suhu } & \multirow[b]{2}{*}{$\begin{array}{l}\text { Rata-rata vigor } \\
\text { terhadap kadar } \\
\quad \text { air }\end{array}$} \\
\hline & $\begin{array}{c}\text { Ruang } \\
\left(27^{\circ} \mathrm{C}-30{ }^{\circ} \mathrm{C}\right)\end{array}$ & $\begin{array}{c}\text { Dingin } \\
\left(5^{\circ} \mathrm{C}-10{ }^{\circ} \mathrm{C}\right)\end{array}$ & $\begin{array}{c}\text { Beku } \\
\left(0^{0} \mathrm{C}-(-5\right. \\
\left.{ }^{0} \mathrm{C}\right)\end{array}$ & \\
\hline $80 \%$ & $0,25^{\mathrm{a}}$ & $0,25^{\mathrm{a}}$ & $0,50^{\mathrm{a}}$ & $0,33^{\mathrm{a}}$ \\
\hline
\end{tabular}




\begin{tabular}{|c|c|c|c|c|}
\hline $85 \%$ & $0,50^{\mathrm{a}}$ & $0,75^{\mathrm{a}}$ & $0,75^{\mathrm{a}}$ & $0,66^{\mathrm{a}}$ \\
\hline $90 \%$ & $0,25^{\mathrm{a}}$ & $0,50^{\mathrm{a}}$ & $0,50^{\mathrm{a}}$ & $0,41^{\mathrm{a}}$ \\
\hline $\begin{array}{c}\text { Rata-rata vigor } \\
\text { terhadap suhu }\end{array}$ & $0,33^{\mathrm{a}}$ & $0,50^{\mathrm{a}}$ & $0,58^{\mathrm{a}}$ & \\
\hline
\end{tabular}

Angka-angka pada kolom dan baris yang sama yang diikuti oleh huruf yang sama tidak berbeda nyata pada uji DMRT taraf $5 \%$

\subsection{Viabilitas}

Grafik persentase viabilitas umbi bibit bawang merah selama penyimpanan 8 minggu dapat dilihat pada Gambar 2.

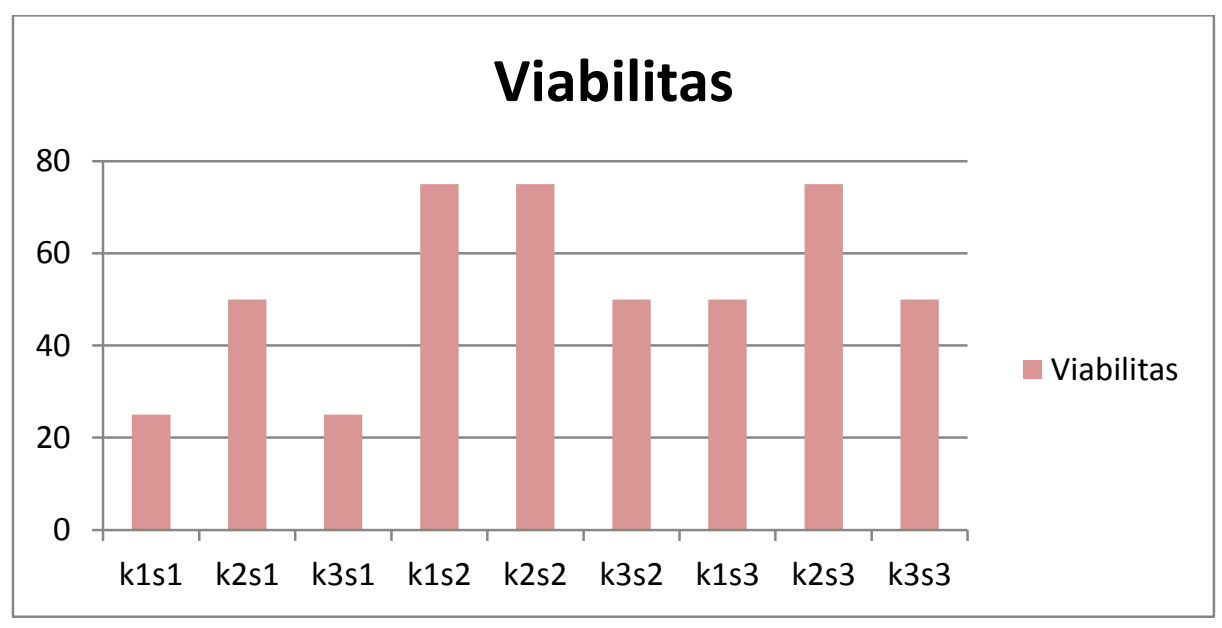

Ket: K1= Kadar air yang hilang 80\%, K2= Kadar air yang hilang 85\%, K3= kadar air yang hilang $90 \%$

$\mathrm{S} 1=$ Suhu Ruang $\left(27^{0}-30^{0} \mathrm{C}\right), \mathrm{S} 2=$ Suhu Dingin $\left(5^{0}-10^{\circ} \mathrm{C}\right), \mathrm{S} 3=$ Suhu beku $\left(-5^{0}-0^{0} \mathrm{C}\right)$

Gambar 4 Grafik persentase viabilitas umbi bibit bawang merah selama penyimpanan 8 minggu.

Gambar 4 menunjukan bahwa persentase viabilitas tertinggi terdapat pada perlakuan K1S2, K2S2 dan K2S3 sebesar 75\%. Hal ini diduga kadar air $80 \%, 85 \%$ dan $90 \%$ yang digunakan mampu mempertahankan viabilitasnya, sehingga ketika diberi perlakuan penyimpanan pada suhu dingin $\left(5^{0}-\right.$ $\left.10^{\circ} \mathrm{C}\right)$ dan suhu beku $\left(-5^{0}-0^{0} \mathrm{C}\right)$ umbi bibit bawang merah masih mampu mempertahankan viabilitas selama penyimpanan minggu 8 .
Sutopo (2012), menyatakan bahwa kadar air optimum untuk penyimpanan sebagian besar benih antara 6\%-8\%. Selain itu, Prawiro (2014), menyatakan bahwa kadar air optimal dengan kisaran 80\%-85\% mampu menahan kenaikan persentase pertumbuhan tunas.

Viabilitas terendah terdapat pada perlakuan K1S1 dan K3S1 sebesar 25\%, hal ini diduga karena penyimpanan pada suhu ruang $\left(27^{\circ}\right.$ $\left.30{ }^{\circ} \mathrm{C}\right)$ umbi bibit bawang merah 
masih melakukan proses metabolisme yang melibatkan cadangan makanan yang terdapat didalam umbi selama proses penyimpanan. Mutia at al. (2014) menyatakan bahwa suhu memberikan pengaruh terhadap proses kimiawi seperti laju respirasi yang menyebabkan penguapan yang berlebihan sehingga terjadi penyusutan kadar air pada umbi bibit bawang merah dan menurunya viabilitas selama penyimpanan.
Hasil uji statistik pada Tabel 5, menunjukan bahwa suhu penyimpanan berpengaruh tidak signifikan terhadap viabilitas umbi bibit bawang merah, sedangkan kadar air dan interaksi antara kadar air dan suhu penyimpanan juga berpengaruh tidak signifikan terhadap viabilitas umbi bibit bawang merah selama penyimpanan 8 minggu.

Tabel 5 Pengaruh interaksi kadar air dan suhu penyimpanan terhadap viabilitas umbi bibit bawang merah selama penyimpanan 8 minggu

\begin{tabular}{|c|c|c|c|c|}
\hline \multirow{2}{*}{$\begin{array}{c}\text { Kadar air } \\
\text { yang hilang } \\
(\%)\end{array}$} & $\begin{array}{c}\text { Ruang } \\
\left(27^{0} \mathrm{C}-30^{0} \mathrm{C}\right)\end{array}$ & $\begin{array}{c}\text { Dingin } \\
\left(5^{0} \mathrm{C}-10^{0} \mathrm{C}\right)\end{array}$ & $\begin{array}{c}\text { Beku } \\
\left(0^{0} \mathrm{C}-\left(-5^{0} \mathrm{C}\right)\right.\end{array}$ & $\begin{array}{c}\text { Rata-rata } \\
\text { viabilitas } \\
\text { terhadap kadar } \\
\text { air }\end{array}$ \\
\hline $80 \%$ & $0,25^{\mathrm{a}}$ & $0,75^{\mathrm{a}}$ & $0,50^{\mathrm{a}}$ & $0,50^{\mathrm{a}}$ \\
\hline $85 \%$ & $0,50^{\mathrm{a}}$ & $0,75^{\mathrm{a}}$ & $0,75^{\mathrm{a}}$ & $0,66^{\mathrm{a}}$ \\
\hline $90 \%$ & $0,25^{\mathrm{a}}$ & $0,50^{\mathrm{a}}$ & $0,50^{\mathrm{a}}$ & $0,41^{\mathrm{a}}$ \\
\hline $\begin{array}{c}\text { Rata-rata } \\
\text { viabilitas } \\
\text { terhadap suhu }\end{array}$ & $0,33^{\mathrm{a}}$ & $0,66^{\mathrm{a}}$ & $0,58^{\mathrm{a}}$ & \\
\hline
\end{tabular}

Angka-angka pada kolom dan baris yang sama yang diikuti oleh huruf yang sama tidak berbeda nyata pada uji DMRT taraf $5 \%$.

Hasil sidik ragam keseluruhan parameter (lampiran 3), menunjukan bahwa suhu penyimpanan memberikan pengaruh yang signifikan terhadap parameter kerusakan dan pertumbuhan tunas, sedangkan kadar air dan interaksi antara kadar air dan suhu penyimpanan tidak memberikan pengaruh yang signifikan terhadap parameter kerusakan, pertumbuhan tunas, vigor dan viabilitas umbi bibit bawang merah. Hal ini diduga kadar air yang digunakan merupakan kadar air yang ideal, sehingga ketika diberi perlakuan dengan suhu ruang $\left(27^{\circ} \mathrm{C}\right.$ $\left.30^{\circ} \mathrm{C}\right)$, suhu dingin $\left(5^{\circ} \mathrm{C}-10^{\circ} \mathrm{C}\right)$ dan suhu beku $\left(-5^{0} \mathrm{C}-0^{0} \mathrm{C}\right)$ tidak menunjukan pengaruh yang signifikan. Kuswanto (2007), menyatakan bahwa penyimpanan suhu rendah $5^{\circ} \mathrm{C}$ mampu menahan kenaikan persentase kerusakan umbi bibit bawang merah. 


\section{KESIMPULAN DAN SARAN}

\subsection{Kesimpulan}

Berdasarkan hasil penelitian yang telah dilakukan, maka dapat disimpulkan sebagai berikut:

1. Kadar air yang hilang $85 \%$ memberikan hasil yang baik terhadap vigor dan viabilitas umbi bibit bawang selama penyimpanan 8 minggu.

2. Penyimpanan pada suhu dingin $\left(5^{\circ} \mathrm{C}-10^{\circ} \mathrm{C}\right)$ dan suhu beku $\quad\left(-5^{0} \mathrm{C}-0^{0} \mathrm{C}\right)$ terbukti mampu mempertahankan vigor dan viabilitas umbi

\section{DAFTAR PUSTAKA}

Andreas V. 2013. Pengaruh suhu dan kemasan terhadap mutu bibit bawang merah (Allium ascalonicum L.) [skripsi]. Bogor (ID): Institut Pertanian Bogor

Doijode, S.D. 2001. Seed storage of horticultural crop. Food Products Press, Binghamton.

Hario, Polije. 2009. Penyimpanan Benih. Press. Jakarta

Justice OL, Bass LN. 2002. Prinsip dan Praktek Penyimpanan Benih. Jakarta: Raja Grafindo Persada

Kuswanto, H. 2007. Teknologi Pemperosesan, Pengemasan, dan bibit bawang merah selama penyimpanan 8 minggu.

3. Interaksi antara kadar air dan suhu penyimpanan tidak berbeda nyata terhadap vigor dan viabilitas umbi bibit bawang merah.

\subsection{Saran}

Penelitian selanjutnya disarankan menggunakan umbi bibit bawang merah dengan kadar air yang hilang $85 \%$ yang disimpan pada suhu dingin dan beku untuk melihat kemampuanya menghasilkan anakan umbi yang baru.

Penyimpanan Benih. Kansius. Yogyakarta

Maemunah. 2010. Viabilitas Benih dan Vigor Bawang Merah Pada Beberapa Varietas Setelah Penyimpanan. Jurnal Agroland 17(1): 18-22

Maratul. H. M. 2015. Produksi dan Penyimpanan Benih. Surakarta. Jurnal Teknologi Pertanian

Mutia, A.K. Purwanto. Y.A. dan Pujantoro. L. 2014. Perubahan Kualitas Bawang Merah (Allium ascalanicum L.) Selama Penyimpanan Pada Tingkat Kadar Air dan Suhu yang Berbeda. Jurnal pascapanen 11(2): 108-115 


\section{Nurkomar. 2001. Teknik Penyimpanan Bawang Merah Pasca Panen di jawa Timur. Jurnal Teknologi Pertanian.}

Prawiro, E.A. 2014. Penyimpanan Bibit Bawang Merah (Allium ascalanicum L.) Pada Suhu Rendah dan Perlakuan Kadar Air Awal Untuk mempertahahnkan Mutu. Skripsi. Fakultas Teknologi Pertanian Institut Pertanian Bogor. Bogor.

Sutopo, L. 2012. Teknologi Benih.

Rajawali Press. Jakarta.

Sutopo, L. 2002. Teknologi Benih.

Rajawali Press. Jakarta.

Sopha, G.A \& Basuki, R.S. 2010. Pengaruh Komposisi
Media Semai Lokal Terhadap Pertumbuhan Bibit Bawang Merah Asal Biji (True Shallot Seed) Di Brebes. Jurnal Ilmuilmu Hayati dan Fisik Vol. 12. No. 1- 4

Wibowo, P. 2010. Pertumbuhan dan Produktivitas Galur Harapan Padi (Oriza sativa L.) Hibrida Di Desa Ketaon Kecamatan Banyudono Boyolali. Skripsi. Fakultas Pertanian Universitas Sebelas Maret. Surakarta.

Zahrok, S. 2007. Pengaruh Kadar Air Awal dan Suhu Penyimpanan Terhadap Mutu Fisiologis Benih Kedelai (Glycine max (L.) Merill). Skripsi. Jurusan Biologi Fakultas Sains dan Teknologi Universitas Islam Negeri Malang. Malang. 